\title{
QUANTIFICAÇÃO DA ANGIOGÊNESE INDUZIDA POR TUMOR EM MEMBRANA CORIOALANTÓICA DE EMBRIÃO DE GALINHA
}

\author{
QUANTIFICATION OF TUMOR-INDUCED ANGIOGENESIS ON CHICKEN \\ EMBRYO CHORIOALLANTOIC MEMBRANE
}

\author{
Caroline Tiemi EGOSHI ${ }^{1}$; Diogo ZERBINI $^{1}$; Paulo Henrique UTUMI ${ }^{1}$;

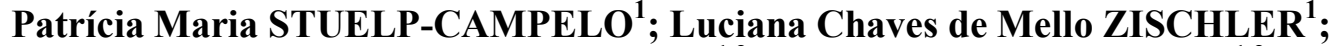 \\ Andréa Novais MORENO-AMARAL ${ }^{1,2}$; Selene ELIFIO-ESPOSITO ${ }^{1,2}$
}

1. Escola de Saúde e Biociências, Pontifícia Universidade Católica do Paraná, Curitiba, PR, Brasil; 2. Programa de pós-graduação em Ciências da Saúde, Escola de Medicina, Pontifícia Universidade Católica do Paraná, Curitiba, PR, Brasil. selene.e@pucpr.br

RESUMO: Angiogênese é um processo de surgimento de novos microvasos provenientes de vasos sanguíneos já existentes. O desenvolvimento tumoral e o processo de metástase são dependentes de angiogênese, pois o tumor em crescimento necessita de uma rede capilar que forneça nutrientes e oxigênio. A membrana corioalantóica de embrião de galinha (CAM) é um modelo experimental in vivo que oferece muitas vantagens, como a alta vascularização natural e alta taxa de reprodução, além de ser um modelo simples e de baixo custo. A CAM é composta por proteínas de matriz extracelular, que mimetizam o ambiente fisiológico de células cancerosas. A etapa de contagem do número total de vasos permite a determinação dos efeitos dos estímulos pró ou anti angiogênicos, portanto a padronização de um método eficaz é necessário. O presente estudo teve como objetivo geral avaliar o potencial angiogênico de células de uma linhagem de adenocarcinoma de cólon humano (HT29) e propor um método para quantificação da angiogênese induzida por células tumorais na CAM. Os embriões foram mantidos em sistema ex ovo. No oitavo dia, foram adicionados sobre a CAM, implantes de colágeno contendo células tumorais em diferentes concentrações. No décimo primeiro dia foi feito o registro fotográfico utilizando microscópio estereoscópico e foram determinados quatro scores para a quantificação e caracterização dos vasos, considerando-se se seccionavam o implante e também seu grau de ramificação. A contagem dos vasos, feita em uma área específica ao redor do implante, foi realizada após edição das imagens pelo programa Image Pro Plus. Os resultados mostraram aumento significativo do número de vasos que não seccionavam o implante para aqueles contendo $3 \times 10^{4}$ e $6 \times 10^{4}$ células. Pode-se concluir que a metodologia de contagem dos vasos, utilizando registros fotográficos e edições de imagens, é eficaz. Demonstrou-se que as células HT29 induzem a uma alteração no padrão de crescimento de novos vasos quando depositada sobre a CAM em implantes de colágeno e podem ser utilizadas como modelo experimental para se investigar o efeito de diferentes compostos sobre a angiogênese induzida por tumor. vascular.

PALAVRAS-CHAVE: Microvasos. CAM. Gallus gallus domesticus. Implante de colágeno. Quantificação

\section{INTRODUÇÃO}

A angiogênese é o processo de geração de novos vasos sanguíneos derivados de um ramo vascular pré-existente (STOCKMANN et al., 2014). No humano adulto a taxa de proliferação das células endoteliais é muito lenta comparada a outros tipos celulares, mas existem ocasiões especiais onde ocorre a expressão controlada de indutores da angiogênese, como no processo de cicatrização de feridas (POLVERINI, 2002; SHIBUYA, 2014).

A angiogênese é um importante fenômeno biológico, alvo terapêutico de diversas condições patológicas (PRATHEESHKUMAR et al., 2012; SUREKHA et al., 2013). É especialmente relevante nas neoplasias malignas onde o tumor em crescimento necessita de uma extensa rede capilar que forneça nutrientes e oxigênio, além disso os novos vasos intratumorais promovem um caminho para vias circulatórias, permitindo assim, a migração celular para órgãos distantes do tumor primário (CHEN et al., 2000; LIEKENS et al., 2001).

Existem diversos modelos experimentais para a investigação de substâncias pró e antiangiogênicas (VEERAMANI; VENI, 2009). Dentre os modelos in vivo o ensaio em membrana corioalantóica de embrião de galinha (CAM) oferece muitas vantagens. É um modelo simples e de baixo custo, que possibilita o estudo do processo complexo da proliferação e migração tumoral. $\mathrm{O}$ embrião serve como um hospedeiro naturalmente imunodeficiente, capaz de sustentar células de diferentes origens sem restrições de especificidade (DERYUGINA; QUIGLEY, 2008; LOKMAN et al., 2012), enquanto que a presença de proteínas da matriz extracelular, como fibronectina, laminina, colágeno do tipo I e integrina $\alpha_{v} \beta_{3}$, faz com que o ambiente fisiológico se assemelhe ao tumoral (LOKMAN et al., 2012). Outra vantagem do ensaio com a CAM é a gama de materiais que podem ser 
utilizados como veículos, como por exemplo discos de papel filtro, agarose, metilcelulose, policrilamida ou colágeno, um polímero natural onde o tecido vascular pode crescer facilmente (FOLKMAN; COTRAN, 1976).

A CAM é uma membrana altamente vascularizada que se desenvolve em torno do conteúdo interno do ovo, separada da parede interna pela membrana da casca. Com a função de promover a troca de gases entre o embrião e a atmosfera circundante, este tecido funciona como o pulmão da ave durante o período embrionário. É formada entre o quarto e sexto dia de desenvolvimento, com a fusão do córion com o alantóide. Possui desenvolvimento rápido e envolve todo o embrião por volta do décimo segundo dia de incubação. Os vasos primitivos continuam a se proliferar e se diferenciar em um sistema arteriovenoso até o oitavo dia, com proliferação rápida até o décimo primeiro dia, quando o índice mitótico passa a decrescer rapidamente (RIBATTI et al., 1996; BLACHER et al., 2005; DERYUGINA; QUIGLEY, 2008; SUBAUSTE et al., 2009; VERHOELST et al., 2011).

Em todos os modelos experimentais de angiogênese a etapa de contagem do número total de vasos e dos neovasos é de suma importância, permitindo assim a determinação dos efeitos dos estímulos pró ou anti angiogênicos, ou efeitos causados por células tumorais. No presente estudo objetivou-se avaliar o potencial angiogênico de células de uma linhagem de adenocarcinoma de cólon humano, além de padronizar um método eficiente de contagem de vasos associados ao tumor.

\section{MATERIAL E MÉTODOS}

\section{Material biológico}

Os ovos de galinha (Gallus gallus domesticus LINNAEUS, 1758) fertilizados foram obtidos da Chácara Amazônia (Curitiba, PR) e foram mantidos em temperatura ambiente, fora do alcance da luz solar, até o momento de incubação. As células de carcinoma de cólon (HT29) foram cedidas pelo Instituto de Patologia e Imunologia da Universidade do Porto (IPATIMUP), Portugal. Foram cultivadas em meio RPMI 1640, suplementado com $10 \%$ de soro fetal bovino, 100 $\mathrm{IU} / \mathrm{ml}$ de penicilina e $0,1 \mathrm{mg} / \mathrm{ml}$ de estreptomicina, em estufa a $37^{\circ} \mathrm{C}$ contendo $5 \%$ de $\mathrm{CO}_{2}$, com troca de meio a cada dois dias e repiques a cada uma semana de cultivo.

\section{Cultivo de embrião de galinha em modelo ex ovo}

Todos os procedimentos de abertura dos ovos e manipulação dos embriões foi realizada sobre condições estéreis em câmara de fluxo laminar. Os ovos foram higienizados com gaze umedecida com água destilada e posteriormente com etanol $70 \%$ e então incubados em chocadeira rotativa automática à $38^{\circ} \mathrm{C}$ (IP $130 \mathrm{D}$, Premium Ecológica, Brasil). No terceiro dia embrionário os embriões foram retirados dos ovos prosseguindo com o desenvolvimento ex ovo. Para tal, uma incisão vertical foi feita na porção média do ovo, com o auxílio de um bisturi até haver um guia para o rompimento da casca (Figura1A e B). O conteúdo interno foi delicadamente depositado em uma barca de pesagem de polipropileno de dimensões $85 \times 85 \times 25 \mathrm{~mm}$ (FiguralC e D) e coberto com uma placa de Petri, evitando qualquer agressão física ou contaminação.

\section{Preparação dos implantes de colágeno}

Os implantes de colágeno foram preparados com base no descrito anteriormente (Deryugina; Quigley, 2008), com modificações. Oito partes uma solução de colágeno tipo I (3 mg/ml; Rat tail, Gibco), esterilizado por irradiação UV em fluxo laminar por 20 minutos, foram misturadas a uma parte de PBS 10X e uma parte de $\mathrm{NaOH} 1 \mathrm{M}$, ambas soluções estéreis, para ajuste do $\mathrm{pH}$ entre 7,2 e 7,4. A solução neutralizada foi mantida em gelo, pois o colágeno passa de um liquido fluido para viscoso rapidamente à temperatura ambiente (SEANDEL et al., 2001; DERYUGINA; QUIGLEY, 2008).

Células da linhagem HT29 em estado de semi-confluência foram desaderidas das garrafas de cultivo pela adição de EDTA $2 \mathrm{mM}$ e lavadas com meio de cultura RPMI 1640 por duas vezes. Após contagem das células em hemocitômetro estas foram misturadas à solução de colágeno neutralizado até os valores finais de $1 \times 10^{4}, 3 \times 10^{4}$ e $6 \times 10^{4}$ células $/ 30 \mu$. Como controle foram preparados implantes sem células. Alíquotas de $30 \mu \mathrm{l}$ foram pipetadas sobre cortes de nylon de $3 \times 3 \mathrm{~mm}$. Estes permaneceram 45 minutos em estufa a temperatura de $37^{\circ} \mathrm{C}$ para polimerizarem.

Os implantes polimerizados foram depositados sobre a CAM no oitavo dia de desenvolvimento. Cada embrião recebeu quatro implantes de colágeno, sendo um controle e três com quantidade diferente de células. Esta aplicação foi realizada cuidadosamente, evitando qualquer agressão a algum vaso, utilizando uma pinça de ponta fina. Os implantes foram adicionados sempre ao lado de um vaso calibroso. Os embriões voltaram à chocadeira por um período de mais três dias (décimo primeiro dia embrionário). Os ensaios foi 
repetidos de forma a se obter um total de pelo menos seis réplicas técnicas no total para cada condição.

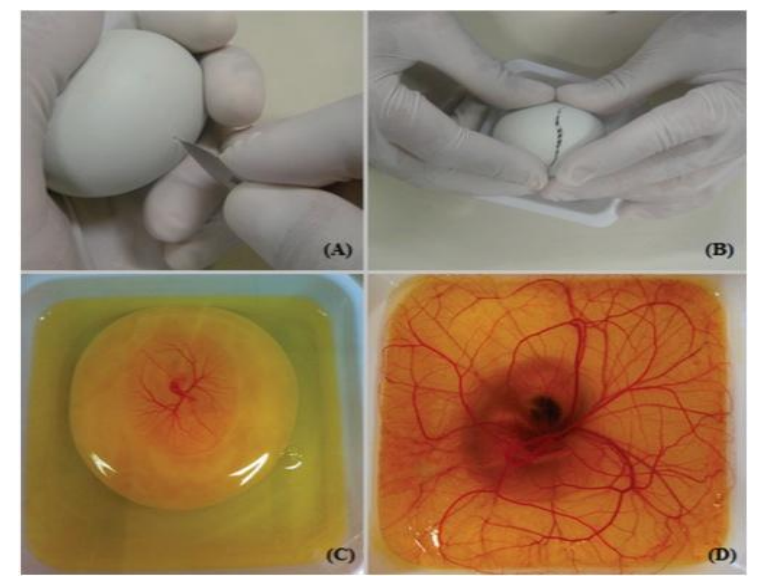

Figura 1. Desenvolvimento dos embriões em sistema ex ovo. A) No terceiro dia de desenvolvimento os embriões foram retirados da casca do ovo com auxilio de uma lâmina de bisturi e B) transferidos para barcas de pesagem de polipropileno. C) Verifica-se a CAM em formação ao redor do embrião logo após a transferência e D) a extensa rede vascular no $11^{\circ}$. dia de desenvolvimento embrionário.

\section{Contagem dos vasos}

No $11^{\circ}$. dia de desenvolvimento os embriões foram fotografados, com destaque para a área ao redor dos implantes, utilizando-se câmera digital Cybershot DCS-T90 (Sony; 12.1 megapixels), acoplada a um microscópio

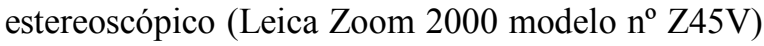
em magnitude de $22,5 \mathrm{X}$. As fotos foram redimensionadas e editadas para ajuste do contraste utilizando-se o programa Image Pro Plus (Media Cybernetics, USA), para facilitar a visualização dos vasos (Figura2A). A função de régua foi utilizada para medição do comprimento linear do implante e, a partir das margens deste, foi demarcado uma região com comprimento equivalente à metade deste. Nesta área foi feita a inversão de cores para a quantificação do total dos vasos (Figura2B) e também a classificação destes em quatro diferentes scores. Foram estabelecidos os seguintes critérios: score 0 , quando o vaso não seccionava o implante $\mathrm{e}$ desconsidera-se qualquer ramificação, score 1 , o vaso seccionava o implante e não apresentava ramificação dentro da área estudada, score 2, o vaso seccionava o implante e apresentava uma ramificação dentro da área, e score 3, o vaso seccionava o implante e apresentava duas ou mais ramificações dentro da área. Durante a contagem os vasos foram sendo coloridos de acordo com a classificação determinada anteriormente, para facilitar a visualização e para que não houvesse contagem dobrada. As cores escolhidas foram: preto para o score 0 , amarelo para o score 1 , vermelho para o score 2 e branco para o score 3 (Figura 2C).
As etapas experimentais seguiram os princípios éticos da experimentação animais e o projeto foi analisado e aprovado pelo Comitê de ética no uso de animais da PUCPR (CEUA/PUCPR parecer 603/2011).

\section{Análise estatística}

Para análise os resultados encontrados para o grupo controle foram comparados com os encontrados para as diferentes grupos experimentais. A análise de variância foi feita por ANOVA e a diferença entre os grupos $(n=6)$ pelo teste de Tukey, utilizando o programa Statistica 5.1.1.

\section{RESULTADOS E DISCUSSÃO}

Durante o desenvolvimento embrionário a CAM se expande e se desenvolve com um grande aumento no número de vasos sanguíneos, acompanhando a necessidade respiratória do embrião (Figura1C e $1 \mathrm{D}$ ). A porção central se desenvolve completamente entre o oitavo e o décimo dia, enquanto a porção periférica continua se desenvolvendo e se expandido até o décimo segundo dia de incubação (RIBATTI et al., 1996; DERYUGINA; QUIGLEY, 2008; VERHOELST et al., 2011). Entre o oitavo e décimo dia, portanto, a membrana corioalantóica em desenvolvimento está pronta para responder a estímulos pró ou antiangiogênicos. 


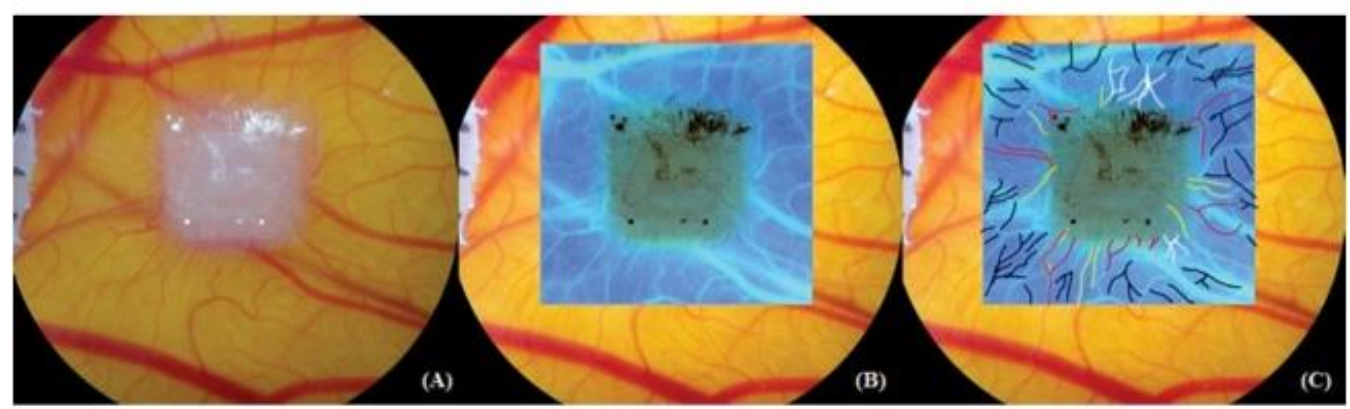

Figura 2. Tratamento dos fotos dos implantes para facilitar a contagem dos vasos. A) Fotografia original mostrando o implante de colágeno ao centro. B) Tratamento com a inversão de cores com aumento do contraste e visualização dos vasos em branco. Demarcação da área de contagem dos vasos. C) Padrão de marcação em cores para a contagem dos vasos

No presente trabalho, optou-se pela remoção completa da casca e desenvolvimento fora do ovo (ex ovo), método que possibilita a total visibilidade da CAM e a avaliação direta do processo angiogênico através de microscópio estereoscópio ao longo do desenvolvimento embrionário. A implantação de polímeros de colágenos contidos numa malha de nylon sobre a CAM como suporte para estudo da angiogênese induzida por tumor foi bem descrita por Deryugina e Quigley (2008). Os autores consideraram que as moléculas de colágeno, por serem fortemente carregadas eletricamente, atrairiam os novos vasos formados a partir da vasculatura pré-existente, que cresceriam verticalmente para o interior do implante. Desta forma os novos vasos poderiam ser facilmente discriminados da rede vascular anterior, auxiliando na avaliação dos vasos formados por indução de células tumorais, ao mesmo tempo em que a tela de nylon serviria como um gabarito pra a contagem, permitindo a determinação da relação entre o número de campos contendo vasos pelo total de campos contados. No presente trabalho não foi possível em todos os casos a visualização dos vasos dentro do implante, por isso optou-se pela contagem dos vasos numa área periférica a este.

A edição das fotos facilitou a distinção dos neovasos, considerados como aqueles que apresentavam menor calibre. Para se verificar se o método permitiria demonstrar e quantificar a angiogênese induzida por tumor, células da linhagem HT29, cuja ação angiogênica sobre a CAM já fora demonstrada (KIM et al., 2011), foram incluidas num implante de colágeno em três diferentes concentrações $\left(1 \times 10^{4}, 3 \times 10^{4}\right.$ e $6 \times 10^{4}$ por implante). Como primeiro critério de análise foi contado o total de vasos para cada condição, resultado apresentado na figura $3 \mathrm{~A}$. Verifica-se que não há diferença significativa no total absoluto de vasos para as diferentes quantidades de células por implante. Da mesma forma também não foram observadas diferenças no grau de ramificação daqueles vasos que faziam contato com o implante, classificados nos scores 1, 2 e 3 (dados não mostrados). Sendo assim, esses vasos foram somados, descartando-se a classificação pelo número de ramificações, partindo-se para a comparação entre o total de vasos que faziam contato com o implante (scores 1 a 3 ) e aqueles que cresceram na periferia deste sem contato com o implante (score 0). A figura 3B revela os resultados obtidos e a análise estatística mostra que nas maiores concentrações as células induziram um aumento significativo do número de vasos classificados como score 0 quando comparadas com o controle, e também quando comparadas entre si, com número de vasos maior para a densidade de $3 \mathrm{x}$ $10^{4}$ células. Esse resultado sugere que a vascularização do implante ocorreria da periferia para o implante e não deste para a periferia, mas não permite concluir o porque da redução do número de vasos na condição de maior densidade celular. Resultado semelhante foi descrito por Knighton e colaboradores (1977) que implantaram fragmentos de tumor de Walker 256 retirados de nódulos subcutâneos de ratos sobre a CAM e observaram o crescimento tumoral e a mudança da vasculatura por diferentes períodos de desenvolvimento do embrião. Foi demonstrado que os tumores apresentam duas fases distintas independente do dia do implante, onde a fase inicial de $72 \mathrm{~h}$ é caracterizada como avascular, ou seja, não há o crescimento de vasos, e a taxa de crescimento do tumor é muito baixa, seguida então, da fase com rápido crescimento, caracterizada pela invasão de muitos vasos sanguíneos (KNIGHTON et al., 1977). 

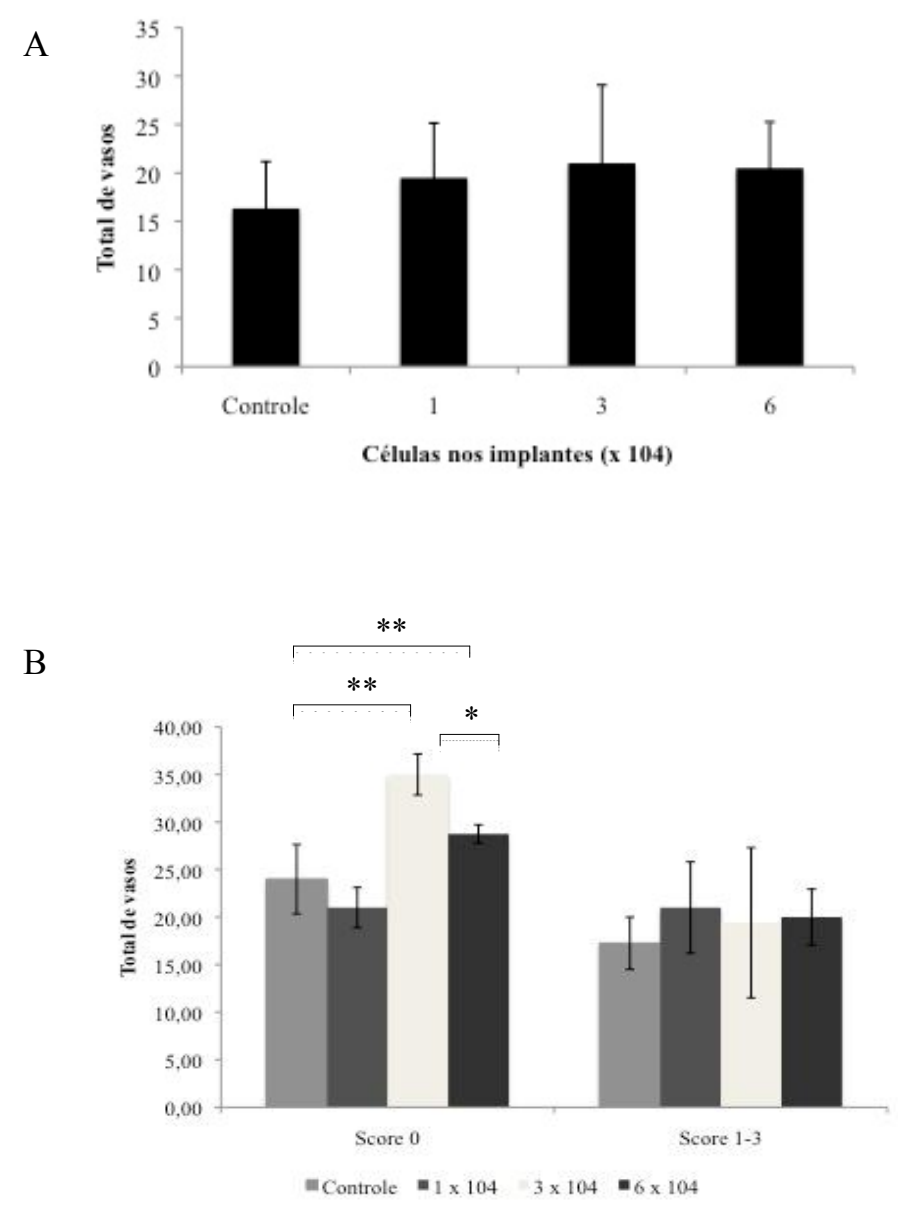

Figura 3. Quantificação dos vasos. A) Média do número total de vasos para os diferentes grupos experimentais. B) Classificação dos vasos nos grupos experimentais, em diferentes scores, distinguindo apenas o score 0 dos demais, que foram contabilizados juntamente.

Diferentes métodos podem avaliar parâmetros distintos em relação a angiogênese, como por exemplo, a área do vaso, o comprimento ou medições complexas, que incluem parâmetros individuais como pontos finais de vasos, número de vasos desenhados, comprimento dos capilares arranjados radialmente durante a vasculogênese (RIBATTI, 2010). Geralmente, as medições complexas são realizadas automaticamente, através de programas de sofisticados, porém são mais indicados para quantificação quando há uma grande mudança na conformação dos vasos, pois não são capazes de identificar diferenças sutis (BLACHER et al., 2005; BROWN et al., 2008).

$O$ presente trabalho destaca o uso de contagem manual, com auxílio de fotografias dos implantes contendo células de linhagem tumoral na membrana corioalantóica, que parecem mimetizar os efeitos gerados pelo implante de tumores primários. Para este método e modelo experimental, normalmente a quantificação é feita sob baixa ampliação, contando todos os vasos ou apenas alguns (BLACHER et al., 2005). O método proposto não somente avalia o número total dos vasos encontrados, como também os classifica em diretamente relacionados com o implante ou não relacionados diretamente.

$\mathrm{O}$ uso de imagens para a quantificação e classificação de vasos não é uma proposta nova. Knighton e colaboradores (1977) mediram as mudanças na distribuição e densidade de vasos na CAM próximos ao implante avaliados in vivo usando um estereomicróscopio a intervalos de tempo regulares, aplicando diferentes classificações para os vasos, considerando a distribuição apresentada mais como um perfil geral e não a quantificação total. Outros autores também calcularam um índice vascular considerando a densidade de ramificação dos vasos utilizando diferentes critérios (FOLKMAN; COTRAN, 1976; FRIEDLANDER et al., 1995; CHEN et al., 2000), o que demonstra que não somente o número total de vasos, mas também a disposição destes com referências ao implante, podem dar indícios sobre os 
mecanismos de formação dos novos vasos e do efeito dos estímulos testados. Fica também evidente a dificuldade na padronização de uma técnica que se aplique a qualquer procedimento empregando a CAM para a investigação vascular.

Por fim, cabe destacar que a técnica proposta contempla ensaios onde o estímulo aplicado fica originalmente situado numa base central ou um guia, que poderia ser um implante com papel filtro ou metilcelulose (LOKMAN et al., 2012), assim havendo um pivô para a criação da área de análise. $\mathrm{O}$ método de contagem não apresentará uma eficácia significativa, em testes que utilizam um veiculo que se dispersa na CAM junto com o estimulo a ser testado (PRATHEESHKUMAR et al., 2012; SINNING et al., 2012).

$\mathrm{O}$ uso da CAM como um modelo experimental versátil já está comprovado. Mesmo tendo sido inicialmente proposto há diversas décadas, continua sendo uma alternativa atual para a investigação in vivo de variados processos fisiológicos, incluindo a angiogênese. O presente trabalho apresenta uma proposta metodológica simples, rápida é barata para a análise vascular que poderá ser empregada para a investigação do potencial angiogênico de diferentes tipos celulares.

\section{AGRADECIMENTOS}

Agradecemos à Fundação Araucária/PR pela concessão das bolsa de Iniciação Científica aos alunos Caroline Egoshi e Paulo Henrique Utumi, e à Pontifícia Universidade Católica do Paraná (PUCPR) pela concessão das bolsa de doutorado à Profa. Luciana Zischler.

\begin{abstract}
Angiogenesis is a process of sprouting of new microvessels from existing blood vessels. The tumoral development and the metastasis process are angiogenesis dependent, because the growing tumor needs a capillaries network that provides nutrients and oxygen. The chicken chorioallantoic membrane (CAM) is an experimental in vivo model which offer many advantages, such as the high natural vascularization and high reproducibility, besides the simplicity and low cost. The CAM contains extracellular matrix proteins, which mimics the physiological cancer cell environment. The counting of the total number of vessels allows a determination of pro- and anti-angiogenic effects of different stimulus, therefore patterning an effective method is necessary. The general goal of the present study was to evaluate the angiogenic potential of a human colon adenocarcinoma cell line (HT29) and propose a method to quantify angiogenesis induced by cancer cells on the CAM. Embryos were cultivated in an ex ovo system. At the eighth day, collagen implants containing cancer cells in different concentrations were added on the top of CAM. At the eleventh day, the photographic records were made by using stereoscope microscope and were determined four scores for vessels quantification and characterization. Vessels counting were done in a specific area around the implant, and edition of the captured images were done using Image Pro Plus software. Our results showed a significant increase in vessels that do not section the implant. It was demonstrated that HT29 cells induce a change in the pattern of growth of new blood vessels when placed on CAM into collagen implants and can be used as an experimental model for investigating the effect of different compounds on tumor-induced angiogenesis.
\end{abstract}

KEYWORDS: Microvessels. CAM. Gallus gallus domesticus. Collagen implant. Vascular quantification.

\title{
REFERÊNCIAS
}

BLACHER, S.; DEVY, L.; HLUSHCHUK, R.; LARGER, E.; LAMANDÉ, N.; BURRI, P.; CORVOL, P.; DJONOV, V.; FOIDART, J. M.; NOËL, A. Quantification of angiogenesis in the chicken chorioallantoic membrane (CAM). Image Analysis Stereology, Lausanne, v. 24, n. 3, p. 169-180, 2005.

http://dx.doi.org/10.5566/ias.v24.p169-180

BROWN, M. C.; STANISZEWSKA, I.; DEL VALLE, L.; TUSZYNSKI, G. P.; MARCINKIEWICZ, C. Angiostatic activity of obtustatin as alphalbetal integrin inhibitor in experimental melanoma growth.

International Journal of Cancer, London, v. 123, n. 9, p. 2195-2203, 2008.

http://dx.doi.org/10.1002/ijc.23777

CHEN, H.; TREWEEKE, A. T.; WEST, D. C.; TILL, K. J.; CAWLEY, J. C.; ZUZEL, M.; TOH, C. H. In vitro and in vivo production of vascular endothelial growth factor by chronic lymphocytic leukemia cells. Blood, Washington, v. 96, n. 9, p. 3181-3187, 2000. 
DERYUGINA, E.; QUIGLEY, J. Chick embryo chorioallantoic membrane model systems to study and visualize human tumor cell metastasis. Histochemistry and Cell Biology, Berlin, v. 130, n. 6, p. 1119-1130, 2008. http://dx.doi.org/10.1007/s00418-008-0536-2

DERYUGINA, E. I.; QUIGLEY, J. P. Chick embryo chorioallantoic membrane model systems to study and visualize human tumor cell metastasis. Histochemistry and Cell Biology, Berlin, v. 130, n. 6, p. 1119-1130, 2008. http://dx.doi.org/10.1007/s00418-008-0536-2

FOLKMAN, J.; COTRAN, R. Relation of vascular proliferation to tumor growth. International Review of Experimental Pathology, Massachusetts, v. 16, n. p. 207-248, 1976.

FRIEDLANDER, M.; BROOKS, P. C.; SHAFFER, R. W.; KINCAID, C. M.; VARNER, J. A.; CHERESH, D. A. Definition of two angiogenic pathways by distinct alpha v integrins. Science, New York, v. 270, n. 5241, p. 1500-1502, 1995. http://dx.doi.org/10.1126/science.270.5241.1500

KIM, T. H.; HUR, E. G.; KANG, S. J.; KIM, J. A.; THAPA, D.; LEE, Y. M.; KU, S. K.; JUNG, Y.; KWAK, M. K. NRF2 blockade suppresses colon tumor angiogenesis by inhibiting hypoxia-induced activation of HIF1alpha. Cancer Research, Philadelphia, v. 71, n. 6, p. 2260-2275, 2011. http://dx.doi.org/10.1158/00085472.CAN-10-3007

KNIGHTON, D.; AUSPRUNK, D.; TAPPER, D.; FOLKMAN, J. Avascular and vascular phases of tumour growth in the chick embryo. British Journal of Cancer, London, v. 35, n. 3, p. 347-356, 1977.

http://dx.doi.org/10.1038/bjc.1977.49

LIEKENS, S.; DE CLERCQ, E.; NEYTS, J. Angiogenesis: regulators and clinical applications. Biochemistry and Pharmacology, Los Angeles, v. 61, n. 3, p. 253-270, 2001. http://dx.doi.org/10.1016/S00062952(00)00529-3

LOKMAN, N. A.; ELDER, A. S.; RICCIARDELLI, C.; OEHLER, M. K. Chick Chorioallantoic Membrane (CAM) Assay as an In Vivo Model to Study the Effect of Newly Identified Molecules on Ovarian Cancer Invasion and Metastasis. International Journal of Molecular Science, British Columbia, v. 13, n. 8, p. 99599970, 2012. http://dx.doi.org/10.3390/ijms13089959

POLVERINI, P. J. Angiogenesis in health and disease: insights into basic mechanisms and therapeutic opportunities. Journal of Dental Education, Washington, v. 66, n. 8, p. 962-975, 2002.

PRATHEESHKUMAR, P.; BUDHRAJA, A.; SON, Y. O.; WANG, X.; ZHANG, Z.; DING, S.; WANG, L.; HITRON, A.; LEE, J. C.; XU, M.; CHEN, G.; LUO, J.; SHI, X. Quercetin Inhibits Angiogenesis Mediated Human Prostate Tumor Growth by Targeting VEGFR-2 Regulated AKT/mTOR/P70S6K Signaling Pathways. PLoS One, San Francisco, v. 7, n. 10, p. e47516, 2012. http://dx.doi.org/10.1371/journal.pone.0047516

PRATHEESHKUMAR, P.; BUDHRAJA, A.; SON, Y. O.; WANG, X.; ZHANG, Z.; DING, S.; WANG, L.; HITRON, A.; LEE, J. C.; XU, M.; CHEN, G.; LUO, J.; SHI, X. Quercetin Inhibits Angiogenesis Mediated Human Prostate Tumor Growth by Targeting VEGFR- 2 Regulated AKT/mTOR/P70S6K Signaling Pathways. PloS one, San Francisco, v. 7, n. 10, p. e47516, 2012.

RIBATTI, D. (2010). The Chick Embryo Chorioallantoic Membrane in the Study of Angiogenesis and Metastasis: The CAM Assay in the Study of Angiogenesis and Metastasis, Basel, Springer.

http://dx.doi.org/10.1007/978-90-481-3845-6

RIBATTI, D.; VACCA, A.; RONCALI, L.; DAMMACCO, F. The chick embryo chorioallantoic membrane as a model for in vivo research on angiogenesis. The International Journal of Developmental Biology, Vizcaya, v. 40, n. 6, p. 1189-1197, 1996. 
SEANDEL, M.; NOACK-KUNNMANN, K.; ZHU, D.; AIMES, R. T.; QUIGLEY, J. P. Growth factor-induced angiogenesis in vivo requires specific cleavage of fibrillar type I collagen. Blood, Washington, v. 97 , n. p. $2323-2332,2001$.

SHIBUYA, M. VEGF-VEGFR Signals in Health and Disease. Biomolecules and Therapeutics, Seoul, v. 22, n. 1, p. 1-9, 2014. http://dx.doi.org/10.4062/biomolther.2013.113

SINNING, M.; LETELIER, R.; ROSAS, C.; FUENZALIDA, M.; LEMUS, D. Angiogenic potential of the cerebrospinal fluid (CSF) of patients with high-grade gliomas measured with the chick embryo chorioallantoic membrane assay (CAM). Biological Research, London, v. 45, n. 2, p. 135-138, 2012.

http://dx.doi.org/10.4067/S0716-97602012000200005

STOCKMANN, C.; SCHADENDORF, D.; KLOSE, R.; HELFRICH, I. The Impact of the Immune System on Tumor: Angiogenesis and Vascular Remodeling. Frontiers in Oncology, Lausanne, v. 4, n. p. 69, 2014.

SUBAUSTE, M. C.; KUPRIYANOVA, T. A.; CONN, E. M.; ARDI, V. C.; QUIGLEY, J. P.; DERYUGINA, E. I. Evaluation of metastatic and angiogenic potentials of human colon carcinoma cells in chick embryo model systems. Clin Exp Metastasis, London, v. 26, n. 8, p. 1033-1047, 2009. http://dx.doi.org/10.1007/s10585-0099293-4

SUREKHA, K. L.; WAGHCHOUDE, M.; GHASKADBI, S. Enhancement of angiogenesis by a 27 kDa lectin from perivitelline fluid of horseshoe crab embryos through upregulation of VEGF and its receptor. Journal of Natural Products, Cincinnati, v. 76, n. 1, p. 117-120, 2013. http://dx.doi.org/10.1021/np3005198

VEERAMANI, V. P.; VENI, G. An essential review on current techniques used in angiogenesis assays. International Journal Pharmtech Research, India, v. 2, n. 4, p. 2379-2387, 2009.

VERHOELST, E.; DE KETELAERE, B.; BRUGGEMAN, V.; VILLAMOR, E.; DECUYPERE, E.; DE BAERDEMAEKER, J. Development of a fast, objective, quantitative methodology to monitor angiogenesis in the chicken chorioallantoic membrane during development. The International Journal of Developmental Biology, Vizcaya, v. 55, n. 1, p. 85-92, 2011. 